Paula Francezca Padua, MD

William L. Lim, MD

Department of Otolaryngology

Head and Neck Surgery

St. Luke's Medical Center
Correspondence: Dr. Paula Francezca Padua

Department of Otolaryngology

Head and Neck Surgery

St. Luke's Medical Center

279 E. Rodriguez Ave., Quezon City 1102

Philippines

Phone: (632) 7275543

Fax: (632) $7231199(\mathrm{H})$

Email: slmcearnosethroat@yahoo.com

The authors declared that this represents original material that is not being considered for publication or has not been published or accepted for publication elsewhere in full or in part, in print or electronic media; that the manuscript has been read and approved by the authors, that the requirements for authorship have been met by each author, and that the authors believe that the manuscript represents honest work.

Disclosures: The authors signed a disclosure that there are no financial or other (including personal) relationships, intellectual passion, political or religious beliefs, and institutional affiliations that might lead to a conflict of interest.

Presented at the Philippine Society of Otolaryngology Head and Neck Surgery Inter Hospital Grand Rounds. September 2, 2015. Makati Medical Center, Makati City.

\section{Relapsing Polychondritis Initially Presenting with Hoarseness and Difficulty Breathing in a 21-Year-Old Male}

\begin{abstract}
Objective: To present a case of relapsing polychondritis initially presenting with hoarseness and difficulty breathing and to discuss the diagnostic criteria and typical CT scan findings of relapsing polychondritis.
\end{abstract}

\section{Methods:}

Design: Case Report

Setting: Tertiary Private Hospital in Metro Manila

Patient: One

Result: A 21-year-old man who was initially managed as a case of bronchial asthma for persistent hoarseness and recurrent difficulty breathing was found to have severe laryngeal edema on endoscopy, and soft tissue expansion of the cricoid cartilage with calcifications and irregular first tracheal ring on CT scan. He also had recurrent eye redness and developed bilateral aural inflammation, and was subsequently diagnosed to have relapsing polychondritis.

Conclusion: Relapsing polychondritis is a rare autoimmune disease characterized by recurrent inflammation and eventual destruction of cartilage throughout the body. Typical manifestations may not always be present, causing a delay in diagnosis. It should be considered in patients with intractable respiratory symptoms not responsive to treatment for upper respiratory tract infections or asthma. A CT scan may reveal signs of cartilage destruction and help in diagnosis.

Keywords: Polychondritis, Relapsing; airway involvement; imaging

Relapsing polychondritis (RP) is a rare inflammatory disease primarily affecting proteoglycan-rich structures and cartilaginous tissues of the ear, nose, joints, tracheobronchial tree, and cardiovascular system. ${ }^{1}$ Several diagnostic criteria have be proposed to diagnose relapsing polychondritis including those by McAdam, ${ }^{2}$ Damiani and Levine, ${ }^{3}$ and Michet. ${ }^{4}$

The airways are affected in about $50-70 \%$ of cases of RP but airway involvement as the initial presentation is rare. ${ }^{5}$ In the report of McAdam et al, airway involvement as the initial involvement was seen in only $12 \%$ of cases. ${ }^{2}$ It is rare to find the complete clinical picture of RP causing a delay in its diagnosis.

We present a case of relapsing polychondritis that initially presented with difficulty breathing and hoarseness, and discuss the diagnostic criteria and CT scan findings that were helpful in arriving at a diagnosis.

Philipp J Otolaryngol Head Neck Surg 2016; 31 (2): 41-46

(C) Philippine Society of Otolaryngology - Head and Neck Surgery, Inc. 


\section{CASE REPORT}

A 21-year-old man was seen by an otorhinolaryngologist for progressive hoarseness and difficulty breathing. Symptoms were first experienced $3 \frac{1}{2}$ months prior to consult and the man had been admitted twice at a local hospital and managed as a case of asthma (including one endotracheal intubation). Persistence of hoarseness prompted referral to the ENT specialist who managed him as a case of chronic laryngitis probably secondary to laryngopharyngeal reflux disease. Without resolution of hoarseness, he was referred to our institution.

Flexible laryngoscopy showed severe laryngeal edema and suspicious subglottic stenosis. A CT scan to confirm the stenosis showed "an elongated fluid hypodensity with peripheral enhancement, more pronounced on the left, in the paraglottic fat at the level of the vocal cord with a small component apparently insinuating between the left lateral wall of the pyriform sinus and pharyngeal wall." A "small air-filled laryngocele on the left" was found. The "thyroid lamina was inhomogeneous with some periosteal reactions." The "glottic and subglottic airway was narrowed with undue soft tissue expansion of the cricoid cartilage with the outer margin being calcified." The arytenoid cartilage was "not definitely identified on both sides and apparently blended with the cricoid cartilage." The first tracheal ring was "observed to be irregular." (Figure 1, 2) With an initial impression of laryngocele with subglottic stenosis, he was admitted for direct laryngoscopy and tracheostomy.

Intraoperatively, there was severe laryngeal edema but no subglottic stenosis was observed. Upon laser incision of the left vocal fold, a soft, yellowish, lipomatous lesion was noted and was biopsied. The left infraglottis was also sampled. The histopathologic report showed "hyperplastic mucosa with benign stromal seromucous glands and adipose tissue fragments on the left false vocal fold that may relate to a submucosal lipogenic lesion, such as a lipoma. The left infraglottic biopsy revealed hyperplastic mucosa with reactive atypia and submucosal myxoid change." Postoperatively, the patient was maintained on oral antibiotics and steroids. He was observed to have bilateral eye redness, which he admitted had waxed and waned for 3 months. Moxifloxacin-dexamethasone eye drops were started by the ophthalmology service and he was discharged on methylprednisolone with a diagnosis of severe laryngeal edema status post tracheostomy, rule out autoimmune disease.

A week after discharge, he developed bilateral aural inflammation (Figure 3) and was referred to the rheumatology service. Although anti native dsDNA, Sm, RNP, and Rheumatoid Factor were all within normal limits (Table 1), a diagnosis of relapsing polychondritis was made on the basis of laryngeal edema, ocular inflammation, and bilateral aural inflammation. He responded very well to immuran, methotrexate, and etanercept and subsequent endoscopies showed a progressive decrease in laryngeal swelling. (Figures 4-6) He still had posterior glottis stenosis and was maintained on tracheostomy but was otherwise well. He was re-admitted approximately a year after in the hopes of possible decannulation. He underwent direct laryngoscopy with microlaryngeal laser surgery of posterior glottic fibrosis. Intraoperatively, the vocal folds were noted to be in median position, with edematous laryngeal mucosa and fibrosis at the posterior glottic interarytenoid area. (Figure 7) Decannulation was deferred due to the high likelihood of recurrence of airway distress. Hence, he was maintained on a tracheotomy button with regular follow-ups.
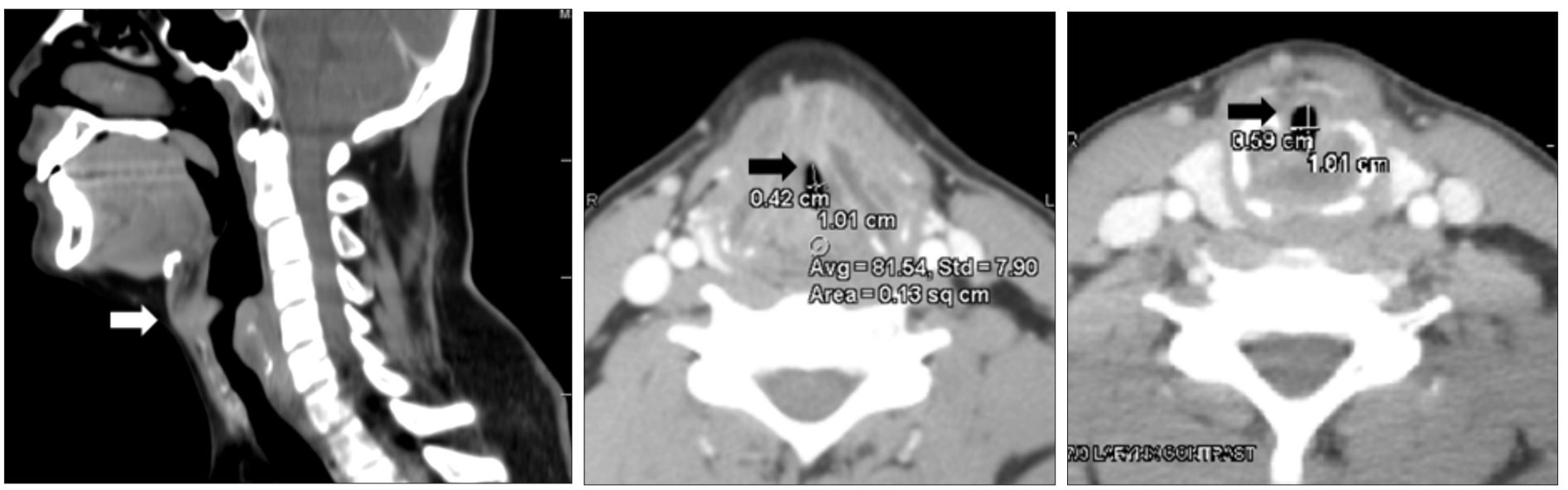

Figure 1. Sagittal and Axial CT scan sections showing glottic and subglottic airway narrowing and irregular first tracheal ring (arrows). 

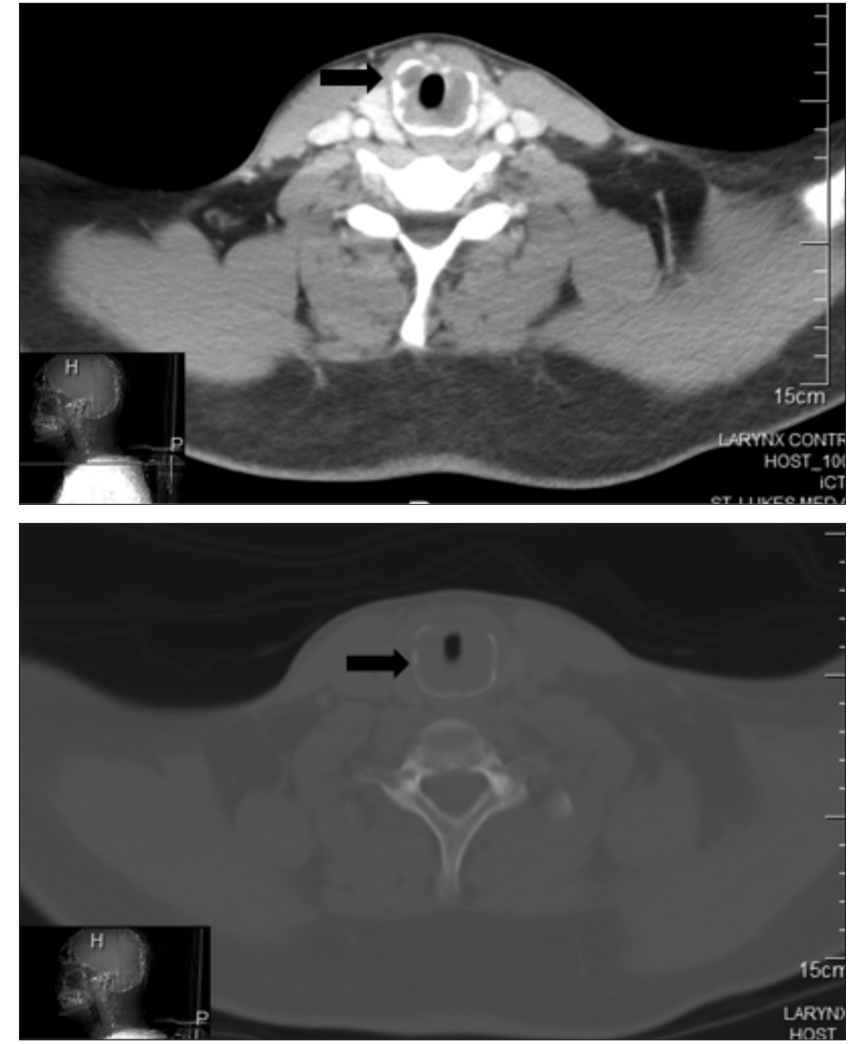

Figure 2. Axial CT scan image showing soft tissue expansion of the cricoid cartilage with the outer margin being calcified (arrows).

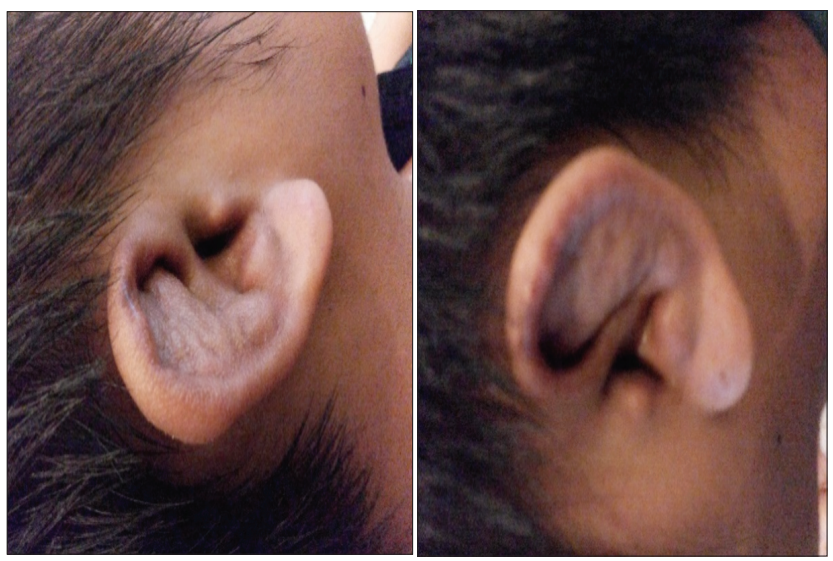

Figure 3. Bilateral aural inflammation

Table 1. Serum Tests

\begin{tabular}{|l|c|c|c|}
\multicolumn{1}{c|}{ Test } & Result & Cut-off & Interpretation \\
\hline Anti native dsDNA & $0.7 \mathrm{U} / \mathrm{ml}$ & $<20$ & Negative \\
\hline Sm & $2.4 \mathrm{U} / \mathrm{ml}$ & $<15$ & Negative \\
\hline RNP & $3.9 \mathrm{U} / \mathrm{ml}$ & $<25$ & Negative \\
\hline Rheumatoid Factor & $<12 \mathrm{IU} / \mathrm{ml}$ & $<12$ & \\
\hline
\end{tabular}

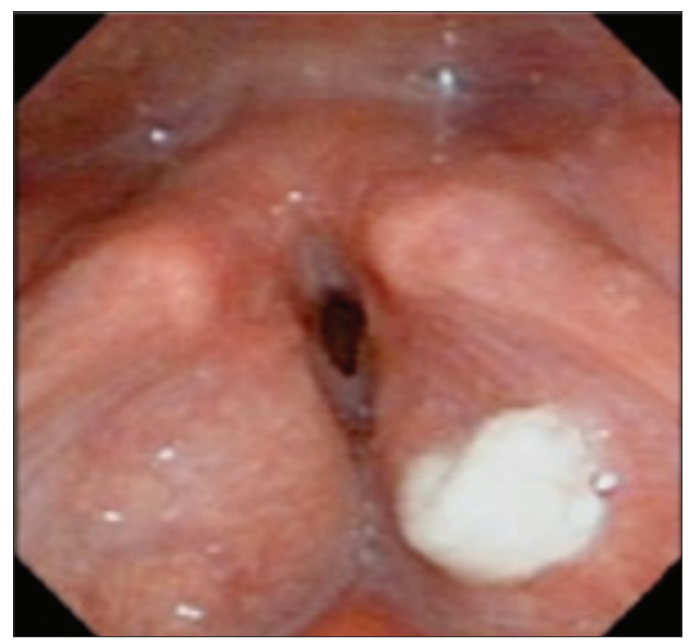

Diffuse laryngeal edema

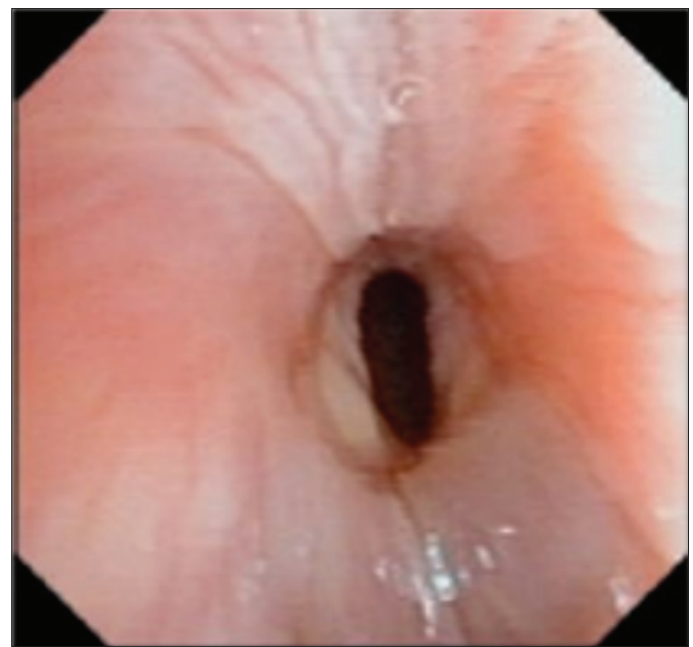

Polypoid vocal folds, subgiottic stenosis

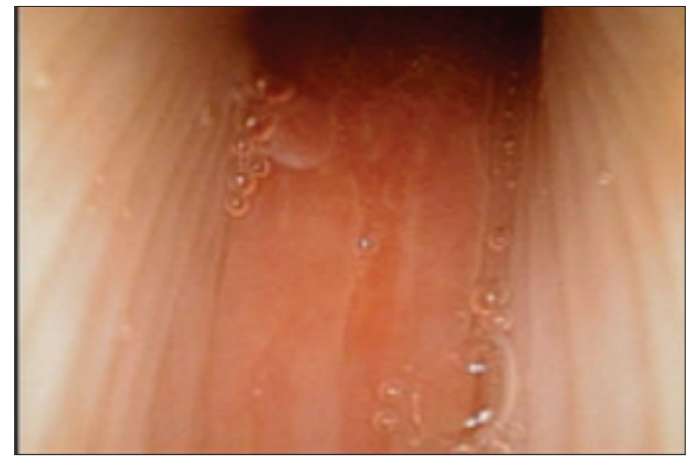

Thickened subgiottic mucosa

Figure 4. Flexible Endoscopy 2 weeks post-op 

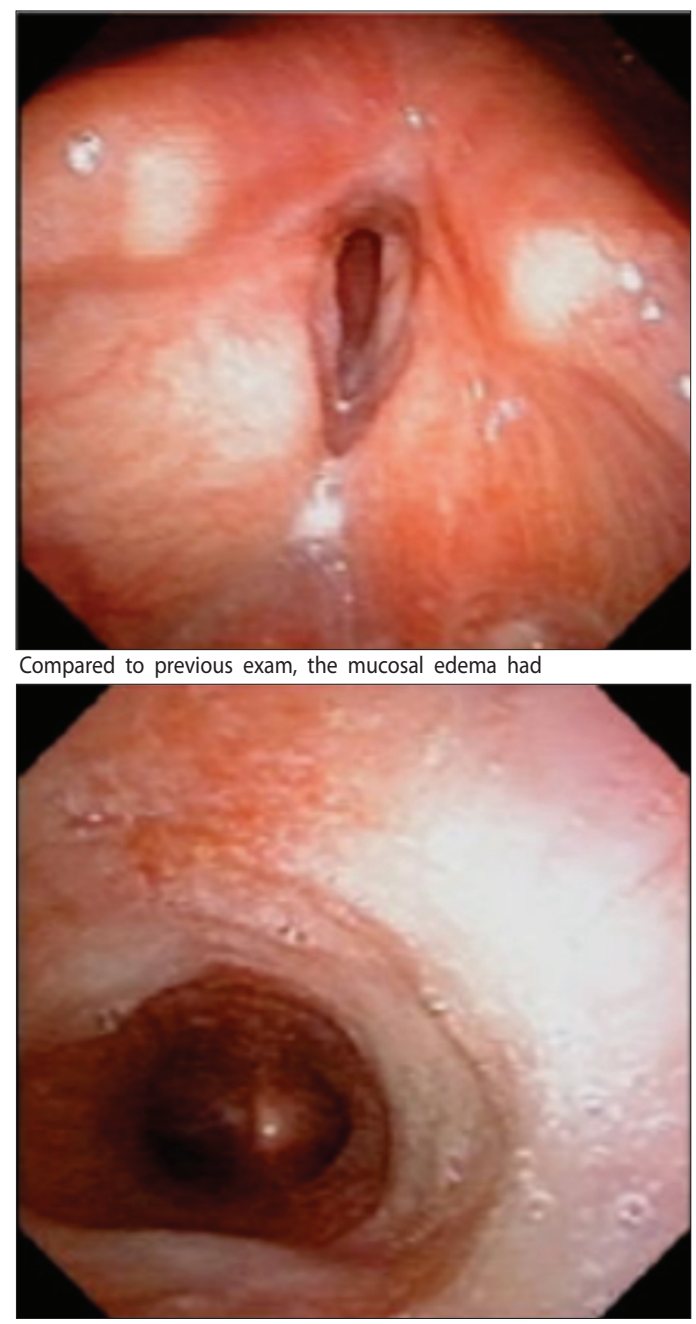

Trachea: normal

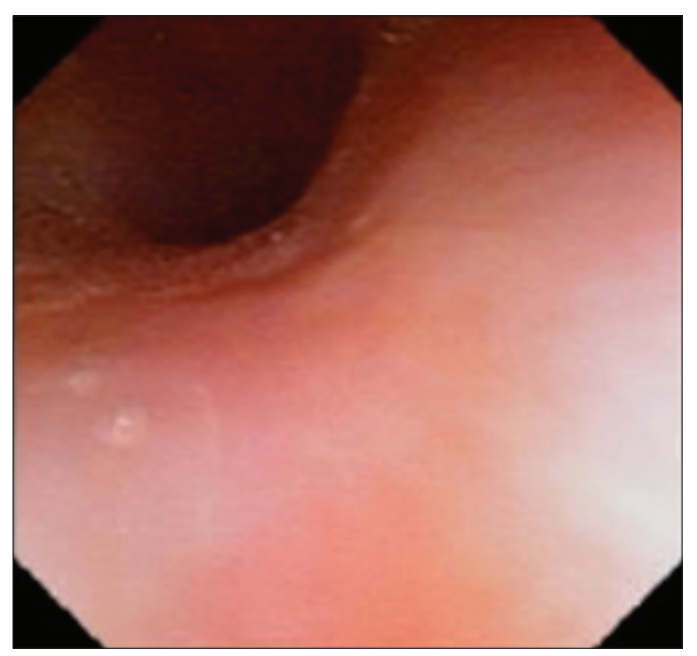

Subglottic view: normal

Figure 5. Flexible Endoscopy 3 weeks post-op

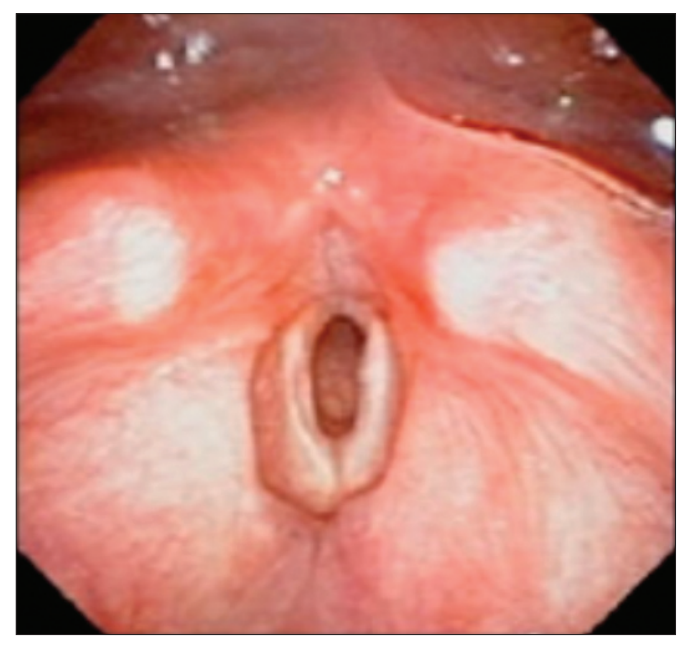

Interarytenoid fibrosis

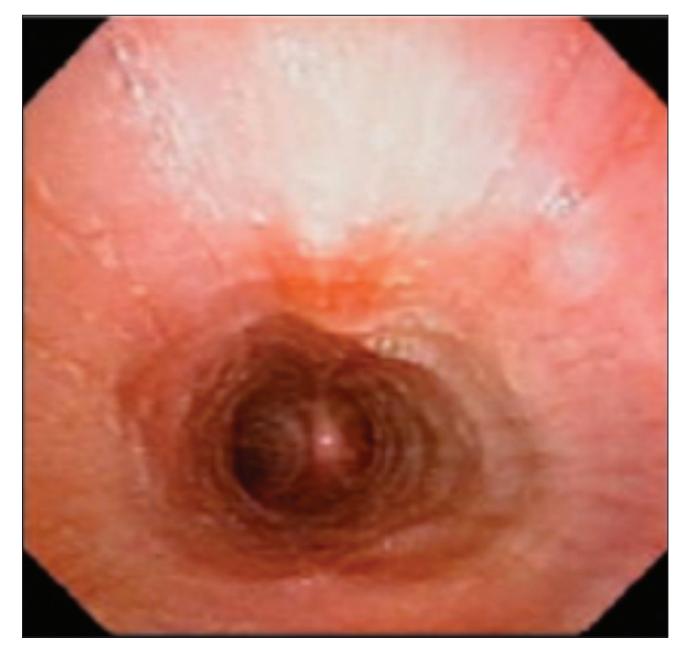

Normal trachea

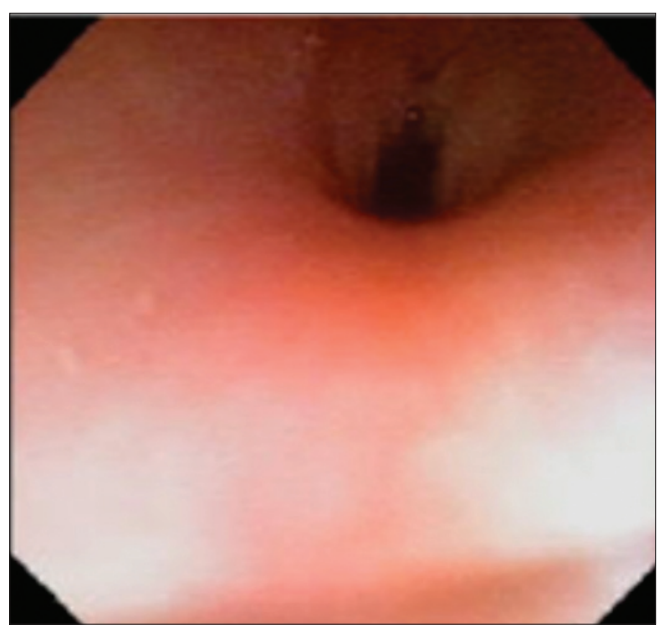

Subglottic view

Figure 6. Flexible Endoscopy 9 weeks post-op 


\section{CASE REPORTS}

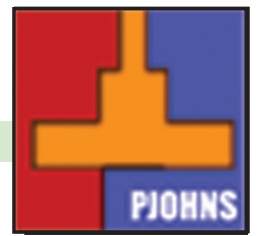

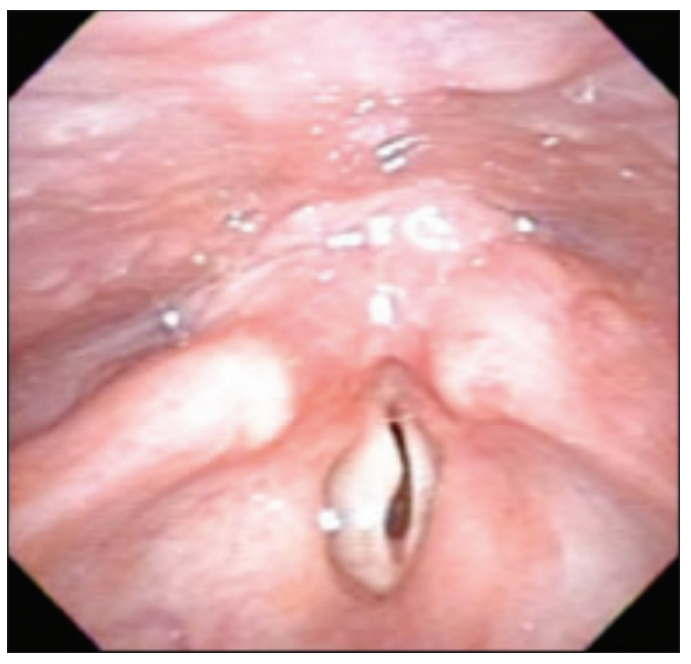

Laryngeal view: Diffuse mucosal edema. Both vocal folds in midline position probably due to cricoarytenoid joints ankylosis or interarytenoid fibrosis.

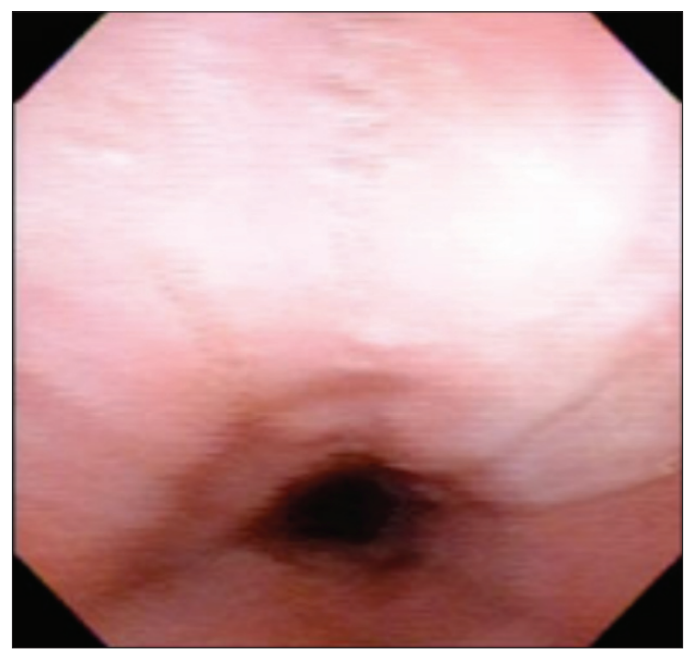

Trancheal view: Edematous mucosa. Tracheal lumen narrowed. Tracheal rings not seen.

Figure 7. Flexible Endoscopy 1 year post-op

\section{DISCUSSION}

Relapsing polychondritis is a rare inflammatory disease primarily affecting proteoglycan-rich structures and cartilaginous tissues of the ear, nose, joints, tracheobronchial tree, and cardiovascular system. ${ }^{1}$ Cardiovascular and respiratory complications of relapsing polychondritis are associated with high morbidity and mortality. ${ }^{6}$

The most frequent initial presentation is inflammation of the pinna on its own, and it is uncommon to see the complete clinical picture of RP (collapsed pinna, nose, larynx, and costal cartilages). ${ }^{7}$ When the initial manifestation of RP involves respiratory symptoms as in our patient, clinical diagnosis is difficult and delayed. ${ }^{8}$ Without other clues to diagnose the disease, we may be misled into thinking of more common diseases, thereby not being able to manage the condition properly.

Our patient initially presented with respiratory tract chondritis and ocular inflammation. Even in retrospect, it would be difficult to diagnose RP based on these two symptoms alone. The picture became clearer with the onset of bilateral aural inflammation, and in conjunction with negative work ups for other diseases, he now fit the Michet ${ }^{4}$ criteria for RP.

Relapsing polychondritis is usually observed in the fourth and fifth decade of life with no sex predilection. ${ }^{6}$ The first diagnostic criteria used, the McAdam criteria required meeting three out of six of the following: bilateral auricular chondritis, nonerosive seronegative inflammatory arthritis, nasal chondritis, ocular inflammation, respiratory tract chondritis, and audiovestibular damage. ${ }^{2}$ This criteria was modified by Damiani and Levine which required meeting one McAdam criterion plus histopathological confirmation or two McAdam criteria plus response to corticosteroids or dapsone. ${ }^{3}$ The most recent and currently used criteria by Michet et al. require the presence of proven inflammation in at least two of three cartilages-- auricular, nasal, or laryngotracheal -- plus two other signs, including ocular inflammation, vestibular dysfunction, seronegative inflammatory arthritis, or hearing loss. ${ }^{4}$

Relapsing polychondritis is not a common disease, and the cause remains unknown. The most commonly involved organs include the ears (85\%), nose (62\%), eyes (54\%), and joints (50-75\%); the airways are affected in $50-70 \%$ of cases. ${ }^{5}$ In the report of McAdam et al., respiratory involvement as the initial presentation is rare, occurring in only $12 \%$ of cases. ${ }^{2}$ As in our case, his patient did not present with the common initial manifestations of the disease, but instead presented with hoarseness and difficulty breathing, which may easily be misdiagnosed as bronchial asthma or other airway diseases. This delay in diagnosis further worsens the prognosis for such type of patients. Without adequate treatment, respiratory tract involvement can be complicated by airway collapse, which is the main cause of death in relapsing polychondritis, accounting for almost $30 \%$ of mortality.

Considering that a high proportion of patients with RP experience respiratory tract complications, $10 \%$ to $21 \%$ of which accounts for the mortality among these patients, ${ }^{9,10}$ it is critically important to diagnose airway involvement early in this population.

The first case report of RP with airway involvement presenting as tracheal collapse was by Purcelli et al. ${ }^{11}$ in 1962. In a case series by McAdam et al. in 1976, the majority of RP patients with a known cause of death had respiratory tract involvement. ${ }^{2}$ Airway compromise may not always be present late in the disease. In a series by Ernst et al., symptomatic airway involvement in RP were the complaints leading to the diagnosis in $21 \%$ of patients. ${ }^{10}$ 


\section{CASE REPORTS}

Respiratory involvement almost always heralds a poorer prognosis since the cause of death is related to respiratory distress in almost half of all reported cases. ${ }^{2}$ Two mechanisms proposed in the development of respiratory distress are: destruction and fibrosis of laryngeal and tracheal cartilage leading to central airway collapse, or inflammation and cicatricial fibrosis leading to peripheral airway narrowing. ${ }^{12}$

How can we diagnose relapsing polychondritis in patients initially presenting with airway involvement? Two diagnostic tools have been suggested.

Bronchoscopy may be useful in identifying the location and assessing the severity of airway disease in RP including making the pathological diagnosis but carries a high risk of respiratory distress and death. ${ }^{9}$

$\mathrm{CT}$ on the other hand, provides excellent resolution of cartilaginous and soft-tissue structures including a detailed anatomic evaluation of both upper and lower airways without the risks that bronchoscopy entails, making it a better option than bronchoscopy at early detection of the disease. ${ }^{12}$

CT findings characteristic of RP are subglottic stenosis, tracheobronchial luminal narrowing, densely calcified and thickened tracheal cartilage, peripheral bronchial narrowing and bronchiectasis, calcifications of the pinnae, and nasal cartilage collapse. ${ }^{12}$

CT manifestations of the airway in RP are increased attenuation and smooth thickening of the airway walls. ${ }^{12}$ Deformity or edema of the tracheal mucosa may be seen as circumferential thickening or a "wormeaten" appearance in an affected cartilage, and in the late stages, the airway lumen may be narrowed, irregular and distorted. ${ }^{5}$ These findings are comparable to what our patient had. His CT scan revealed glottic and subglottic narrowing with a calcified and thickened cricoid cartilage. The first tracheal ring was also found to be irregular in contour.

The diagnosis of RP is largely based on the clinical features, and the role of laboratory and imaging is supportive to rule out other related or associated systemic diseases. However, in at least $12 \%$ of cases, airway involvement may be the initial symptom, with the absence of other clinical features. ${ }^{2}$ In these circumstances, it is difficult to make a diagnosis and RP may not be at the top of the list. Imaging, specifically CT scan, may be requested for further investigation, and possibly an earlier detection of the disease.

In the event that a patient presenting with recurrent cough, dyspnea, hoarseness or stridor becomes unresponsive to traditional treatment for upper airway infection or bronchial asthma, a high index of suspicion for other possible diagnosis such as RP may be considered. It should be kept in mind that airway problems may be one of the presenting symptoms of relapsing polychondritis and this carries a high risk for mortality. Extensive use of diagnostic procedures such as a CT scan may therefore be a prudent action for such cases to help narrow down a possible diagnosis.

\section{REFERENCES}

1. Vitale A, Sota J, Rigante D, Lopalco G, Molinaro F, Messina M, et al. Relapsing polychondritis: An update on pathogenesis, clinical features, diagnostic tools, and therapeutic perspectives. Curr Rheumatol Rep. 2016 Jan;18(1):3. DOI: 10.1007/s11926-015-0549-5 PubMed PMID: 26711694.

2. McAdam LP, O'Hanlan MA, Bluestone R, Pearson CM. Relapsing polychondritis: prospective study of 23 patients and a review of the literature. Medicine. 1976 May;55(3):193-215. PubMed PMID: 775252

3. Damiani JM, Levine HL. Relapsing polychondritis-- report of ten cases. Laryngoscope. 1979 Jun; 89(6 Pt 1): 929-946. PubMed PMID: 449538

4. Michet CJ Jr., McKenna CH, Luthra HS, O'Fallon WM. Relapsing polychondritis. Survival and predictive role of early disease manifestations. Ann Intern Med. 1986 Jan; 104(1): 74-78. PubMed PMID: 3484422

5. Chang SJ, Lu CC, Chung YM, Lee SS, Chou CT, Huang DF. Laryngotracheal involvement as the initial manifestation of relapsing polychondritis. J Chin Med Assoc. 2005 Jun; 68(6): 279-282. DOI: 10.1016/S1726-4901(09)70151-0 PubMed PMID: 15984823

6. Sosada B, Loza K, Bialo-Wojcicka E. Relapsing polychondritis. Case Rep Dermatol Med. 2014 Sep 30. DOI: 10.1155/2014/791951. PubMed PMID: 25349745 PubMed Central PMCID: PMC4198788.

7. Jones NS. Nasal manifestations of rheumatic diseases. Ann Rheum Dis. 1999 Oct; 58(10): 589 590. PubMed Central PMCID: PMC1752786.

8. Gorard C, Kadri S. Critical airway involvement in relapsing polychondritis. BMJ Case Rep. 2014; 2014: bcr2014205036. DOI: 10.1136/bcr-2014-205036. PubMed PMID 25213785 PubMed Central PMCID: PMC4166125.

9. Kawano T, Matsuse H, Kinoshita N, Tsuchida T, Nishino T, Fukushima C, et al. Bronchoscopic observation of unusual deformities of bronchial cartilage and subsequent airway narrowing in respiratory relapsing polychondritis. Am J Case Rep. 2012 Jun; 13: 114-117. DOI: 10.12659/ AJCR.883091 PMCID: PMC3616182.

10. Ernst A, Rafeq S, Boiselle P, Sung A, Reddy C, Michaud G, et al. Relapsing polychondritis and airway involvement. Chest. 2009 Apr; 135(4): 1024-1030. DOI: 10.1378/chest.08-1180 PubMed PMID: 19017885

11. Purcelli FM, Nahum A, Monell C. Relapsing polychondritis with tracheal collapse. Ann Otol Rhinol Laryngol. 1962 Dec; 71: 1120-1129.PubMed PMID: 13972564.

12. Faix LE, Branstetter BF 4th. Uncommon CT findings in relapsing polychondritis. AJNR Am J Neuroradiol. 2005 Sep; 26(8): 2134-2136. PubMed PMID: 16155171. 